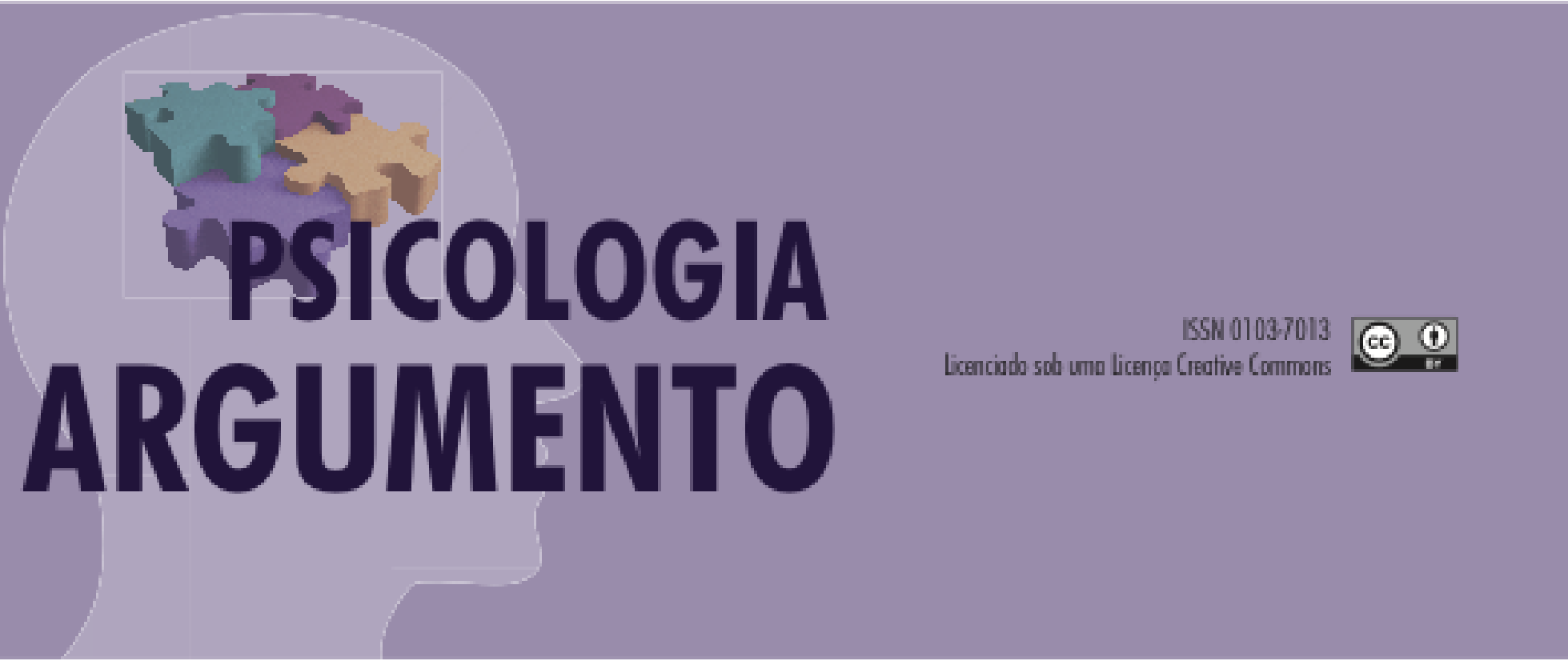

doi 10.7213/psicol.argum.33.081.AO03

\title{
Relação entre práticas parentais e habilidades sociais de crianças do Ensino Fundamental de escola pública
}

Relation between parental practices and social skills of children in a public Elementary School

Hellysana Torquato Paes de Sousa [a], Thaise Löhr-Tacla [b]

[a] Graduada em Psicologia pela Faculdade Evangélica do Paraná. Curitiba, PR, Brasil. hellysana.paes@gmail.com [b] Mestre em Psicologia na Universidade Federal de São Carlos (UFSCar). Professora na Pontifícia Universidade Católica do Paraná (PUC-PR), Curitiba, PR, Brasil. thaiselohr@gmail.com

\section{Resumo}

A família tem importância significativa na educação e no desenvolvimento da criança, agindo no aprendizado de novos repertórios sociais. Este trabalho teve por objetivo verificar a relação entre práticas parentais e habilidades sociais de crianças do $6^{\circ}$ ao $7^{\circ}$ ano do Ensino Fundamental de uma escola pública. Participaram do estudo 28 crianças de 10 a 13 anos de idade, de ambos os sexos. Para acoleta de dados utilizou-se os instrumentos: Inventário de Estilos Parentais (IEP) e Inventário Multimídia de Habilidades Sociais para Crianças (IMHSC). Primeiramente, foi aplicado o IEP, em que a criança deveria responder sobre a frequência com que a figura paterna agiria na situação apresentada. Em seguida, foi aplicado o 
IMHSC, em que o participante deveria indicar a sua reação diante das situações interpessoais apresentadas. Para a análise de dados, foi utilizado o teste qui-quadrado para verificar a correlação estatística entre as variáveis estudadas, considerando a diferença significativa de valor maior ou igual a 0,05 . Como resultado, nas habilidades sociais verificou-se que $100 \%$ dos participantes apresentaram comportamento socialmente habilidoso. Nas práticas parentais, $57 \%$ apresentaram práticas positivas e $43 \%$ práticas negativas. $\mathrm{Na}$ correlação entre as variáveis, verificou-se que independentemente de ser prática positiva ou negativa todos apontaram comportamento social habilidoso. Conclui-se, portanto, que as práticas educativas positivas são as mais utilizadas. No entanto, as duas variáveis devem ser analisadas isoladamente, pois não houve correlação estatisticamente significativa (valor 0,04496) entre habilidades sociais e práticas parentais, ou seja, não se pode afirmar que uma variável pode interferir na outra.

Palavras-chave: Práticas Parentais; Habilidades Sociais; Crianças.

\begin{abstract}
Family plays a key role in the education and human development of children, impacting directly on the acquisition of new social repertories. The present research aims to find out the link between parental practices and the social skills of children from the 6th to the 7th Grade in a Public Elementary School. A total of 28 10-to-13-year-old children took part in the study, both boys and girls. For the data collection, the following tools were employed: Parenting Style Inventory - PSI, and the Children Social Skills Multimedia Inventory - CSSMI. Firstly, in the PSI children should point out how often the parental figure would interfere with the situation presented. Then, the IMHSC should indicate the participant's reaction towards the interpersonal contexts presented. The chi-square test was employed for the data analysis, in order to verify the statistical correlation between the variables studied, considering the value variation as greater than or equal to 0.05 . As a result, $100 \%$ of the participants demonstrated a socially skillful behavior. With regard to parental practices, $57 \%$ of the participants performed positively, while $43 \%$ presented negative practice. The correlation between variables demonstrated that both positive and negative parental practices can produce socially skillful behavior. Through the present research, it was possible to conclude that positive educational practices are the most employed ones. However, both variables must be analyzed separately, once no statistically meaningful correlation (value 0.04496) between social practices and parental practices was evinced, i.e., it is not possible to state that a variable can impact on the other.
\end{abstract}

Keywords: Parental Practices; Social Skills; Children

\title{
Introdução
}

A família é o ambiente social primário da criança. Por isso, ao adotarem comportamentos socialmente apropriados, os pais estão contribuindo para o desenvolvimento do repertório comportamental de seus filhos e propiciando que eles aprendam comportamentos considerados socialmente adequados (Del Prette \& Del Prette, 1999; Ingberman \& Löhr, 2003). Assim, de acordo com Cia, Pereira, Del Prette \& Del Prette (2006), no contexto familiar das relações entre pais e filhos, o desempenho dos pais pode ser representado por meio de habilidades sociais educativas. Silva (2000) citado por Cia et al. (2006), destacou algumas habilidades consideradas essenciais para esse desempenho: (a) diálogo; (b) expressão de sentimentos de agrado e desagrado; (c) solicitação apropriada de mudança de comportamento e expressão de opiniões; (d) cumprimento de promessas; (e) compreensão do casal quanto à educação do filho e à participação de ambos os pais na divisão de tarefas educativas; (f) dizer "não", negociar e estabelecer regras; e (g) desculparse.

Gomide (2011) afirma que quando a criança aprende comportamentos socialmente adequados e os pais se atentam para os aspectos positivos do comportamento dela, consequentemente, o desenvolvimento dos aspectos negativos pode ser inibido devido ao fato de a criança saber o que fazer para atender às expectativas dos pais. Para Gomide (2012), o comportamento pró-social é aprendido por meio de: 
a) Reforçamento - as crianças apresentam comportamentos considerados socialmente apropriados e, diante dessa postura, os pais devem reforçar esses comportamentos por meio de atenção, elogios ou gestos que aprovem essa conduta;

b) Imitações - as crianças costumam observar seus pais e começam a repetir os comportamentos deles;

c) Modelos - os pais são referência para os filhos e, dessa forma, os comportamentos que adotam diante de situações de conflito, normas, regras e resolução de problemas, por exemplo, se tornam referenciais a serem seguidos pela criança;

d) Observações - mesmo na ausência do reforçamento, a observação pode levar à imitação do comportamento (Batista, Oliveira e Pires, 2011).

Skinner (1971) citado por Gomide (2012), afirma que o comportamento de um indivíduo depende do controle desempenhado pelo ambiente social. Dessa forma, estudos afirmam a relevância da contribuição de ambos os pais na educação de seus filhos para propiciar um ambiente social adequado (Fagan \& Iglesias, 1999; Verschueren \& Marcoen, 1999 apud Cia et al., 2006).

Assim, o controle desempenhado pelo ambiente social está diretamente relacionado com os diferentes estilos parentais, que Gomide (2011) define como um conjunto de práticas educativas parentais ou atitudes parentais utilizadas pelos pais para orientar o comportamento dos filhos. As práticas parentais são utilizadas com o objetivo de educar, socializar e controlar o comportamento dos filhos e são entendidas como escolhas educativas que os pais estabelecem em diferentes situações: ensinar, limitar e moldar o comportamento dos filhos. Segundo Gomide (2011), as práticas parentais são divididas em sete, sendo duas positivas (monitoria positiva e comportamento moral) e cinco negativas (abuso físico, disciplina relaxada, monitoria negativa, negligência e punição inconsistente).

As práticas educativas parentais positivas caracterizam-se como "caminhos que levariam os pais a um relacionamento saudável e harmonioso com seus filhos" (Gomide, 2011, p. 7), e também possibilitam a promoção de comportamentos pró-sociais (Gomide, 2003). A monitoria positiva, por sua vez, consiste em um conjunto de práticas parentais que exigem dos pais atenção e conhecimento a respeito dos lugares que o filho frequenta e das atividades que ele desenvolve. Os pais exercem essas práticas por meio de acompanhamento contínuo das atividades escolares e do lazer do filho, por exemplo. A monitoria positiva também é caracterizada pelas demonstrações de afeto e carinho que os pais expressam nos momentos de maior necessidade da criança (Dishion \& McMahon,1998 apud Gomide, 2003). Já o comportamento moral consiste no ensinamento de virtudes, por meio de explicações ou citação de exemplos claros sobre comportamento de risco. Do mesmo modo, os pais têm papel imprescindível no desenvolvimento de valores ao ensinarem os filhos sobre a importância de virtudes como justiça, respeito e honestidade, por exemplo (Gomide, 2012). Segundo Gomide (2012), a aquisição do comportamento moral é um processo que envolve a modelagem de papéis sociais sobre normas e valores fornecidos por meio do modelo parental. Esse comportamento necessita de uma relação permeada pelo afeto. Gomide (2011) acrescenta que o envolvimento dos pais com o comportamento moral dos filhos molda juízos de valores e permite o desenvolvimento da consciência moral, auxiliando diretamente no desenvolvimento e aprendizado desses comportamentos, que, com isso, são moldados a novos repertórios comportamentais.

Por outro lado, as práticas educativas parentais negativas possibilitam o desenvolvimento de comportamentos antissociais (Salvo, Silvares \& Toni, 2005). Conforme 
já mencionado, essas práticas são compostas por cinco variáveis comportamentais: abuso físico, disciplina relaxada, monitoria negativa, negligência e punição inconsistente.

Gomide (2011) aponta que a prática parental negativa abuso físico atinge o ser da criança e não o seu comportamento inadequado, visto que essa é uma prática cujo objetivo é machucar a criança e não discipliná-la. Essa prática parental tem a possibilidade de gerar crianças apáticas, medrosas e desinteressadas, uma vez que a criança não compreende o motivo pelo qual está sendo agredida e, dessa forma, não consegue diferenciar o que é "certo" e o que é "errado" em seu comportamento. Muitas vezes, ela não sabe como reagir, optando em permanecer neutra, com o intuito de impedir a surra. De acordo com World Health Organization (WHO, 2006) e International Society for Prevention of Child Abuse and Neglect (ISPCAN, 2006) citado por Patrian, Rios e Williams (2013), o abuso físico pode ser caracterizado como o uso de força física de forma intencional, e não um ato acidental. Essa prática violenta tem como objetivo maltratar ou machucar a criança ou adolescente, provocando ou não marcas explícitas em seus corpos por meio de chutes, mordidas, queimaduras, espancamentos, intoxicação e sufocamento. O resultado dessa violência, muitas vezes, pode comprometer a saúde, a sobrevivência, a dignidade e o desenvolvimento da criança.

A disciplina relaxada, por sua vez, é caracterizada por Gomide (2003) como sendo o "não cumprimento de regras estabelecidas. Os pais estabelecem as regras, ameaçam e quando se confrontam com comportamentos opositores e agressivos dos filhos abrem mão de seu papel educativo, retirando-se do embate" (p. 36). Com essa prática, os pais, involuntariamente, ensinam aos filhos que não há necessidade de cumprir regras, levandoos à não aceitação das normas sociais, não conscientização dos valores morais ou éticos e falta de respeito às pessoas e aos direitos humanos (Gomide, 2011).

A monitoria negativa, que também pode ser denominada de supervisão estressante, é identificada pela inspeção e por ordens extremas que os pais impõem sobre seus filhos (Gomide, 2011). Essa prática tem o objetivo de inibir o desenvolvimento da autonomia e independência da criança. Os pais que a utilizam procuram controlar excessivamente o comportamento dos seus filhos a fim de manter a dependência emocional (Gomide, 2003). Segundo Gomide (2011), quando a supervisão se torna excessiva, os filhos deixam de prestar atenção às normas, ignorando-as e burlando-as.

A prática parental negativa negligência é caracterizada pelo não comprometimento dos pais em suprir as necessidades emocionais e fisiológicas de seus filhos, agindo com descaso e omissão, ou, simplesmente pela falta de amor. Segundo Gomide (2012), essa prática pode ocorrer de forma sutil ou clara. Para Gomide (2011), a negligência impede o desenvolvimento da autoestima da criança, fazendo-a se sentir insegura e fragilizada. Com isso, consequentemente, a criança pode se comportar de forma apática ou agressiva.

A punição inconsistente é outra prática parental negativa que se caracteriza pela atitude do pai ou da mãe de impor penalidade sobre seu filho independentemente do comportamento adotado por ele. Essa prática ocorre quando os pais punem ou reforçam o comportamento de seus filhos de acordo com o seu estado de humor. Nessa prática, portanto, é o estado emocional dos pais que determina as ações educativas e não o comportamento da criança. Isso, por sua vez, dificulta o aprendizado dela sobre valores, impedindo-a de explorar o ambiente para descobrir o certo e o errado. Dessa forma, quando os pais aplicam punições inconsistentes eles acabam alterando consecutivamente suas opiniões em relação ao que é certo ou errado e, com isso, confundem a criança e acabam contribuindo para que 
ela tenha um comportamento desobediente e desenvolva instabilidade emocional, podendo se tornar ansiosa e/ou agressiva. Em decorrência das sucessivas frustrações, por não acertar o que deveria fazer para agradar aos seus pais, a criança começa a rejeitar as orientações deles e não mais os vê como modelo moral a ser seguido (Gomide, 2011).

Del Prette e Del Prette (1999) apontam que os pais representam modelos que contribuem para o desenvolvimento de padrões comportamentais adequados ou inadequados para os filhos. Assim, quando o repertório socio-habilidoso se torna elevado, a criança tem a possibilidade de estabelecer relacionamentos bem-sucedidos com as demais pessoas. Nesse ponto, Del Prette e Del Prette (2005) descrevem habilidades sociais como classes de comportamentos sociais do repertório de um indivíduo. Del Prette e Del Prette (2011) acrescentam à definição de habilidades sociais:

... classe específica de comportamentos que um indivíduo emite para completar com sucesso uma tarefa social. Tarefas sociais podem incluir entrar em um grupo de colegas, iniciar e manter conversação, fazer amigos, brincar com os amigos etc. ... as habilidades sociais são comportamentos específicos exibidos em situações igualmente específicas que são julgados como competentes ou não no cumprimento da tarefa social (p.19).

Para Del Prette e Del Prette (2011), as habilidades sociais podem ser melhor compreendidas se forem entendidas como uma classe de respostas comportamentais desenvolvidas em um ambiente social. Do ponto de vista da Análise do Comportamento, "uma classe de respostas é um conjunto de comportamentos topograficamente distintos que são funcionais em responder a uma determinada tarefa social." (Del Prette \& Del Prette, 2011, p. 20). Del Prette e Del Prette (2005) compreendem que o comportamento social pode ser dividido em três reações diferentes:

1) Reação habilidosa - também conhecida como assertividade, é caracterizada pela junção de comportamentos abertos (podem ser observados - perguntar, opinar, solicitar mudança de comportamento e fazer pedidos, por exemplo) com comportamentos encobertos (não podem ser observados - pensamentos, sentimentos e desejos, por exemplo). Também, a adaptação adequada desses comportamentos às demandas sociais e consequências adquiridas contribui para a competência social (Del Prette \& Del Prette, 2005);

2) Reação não habilidosa passiva - trata-se de comportamentos que danificam o desempenho socio-habilidoso de um sujeito. Esses comportamentos são expressos por meio de formas encobertas de demonstração de sentimentos (mágoa e ressentimentos, por exemplo) ou são manifestos através da esquiva ou fuga do enfrentamento de uma situação (Del Prette \& Del Prette, 1999);

3) Reação não habilidosa ativa - é caracterizada pelo caráter agressivo (físico ou verbal), pelo negativismo, pela ironia, pelo autoritarismo e pela coerção. Esses comportamentos podem comprometer a competência social do indivíduo (Del Prette \& Del Prette, 2005).

As habilidades sociais, compreendidas como as diferentes classes de comportamentos sociais, contribuem para a competência social e para o desenvolvimento de relacionamentos saudáveis e produtivos de um indivíduo com as demais pessoas, ampliando, assim, seu repertório comportamental (Del Prette \& Del Prette, 2005).

Del Prette, Del Prette e Branco (1992) apontam que a maneira como os pais educam seus filhos é uma condição essencial para a construção da competência social. Segundo Bolsoni-Silva e Marturano (2002), essa educação também pode contribuir para 
comportamentos considerados inadequados, à medida que a família ensina os comportamentos por meio da disciplina. Por isso, os pais precisam exercer reforço para os comportamentos considerados socialmente adequados que os filhos apresentam, fornecendo-lhes elogios e/ou atenção. Desse modo, deve-se observar o funcionamento significativo da educação parental que se exercita sobre a criança.

Diante da importância da família sobre o processo educacional da criança e sua contribuição para o desenvolvimento de um repertório socialmente habilidoso, considerando que o primeiro ambiente social dela é a família, quando mães e pais adotam comportamentos considerados socialmente adequados com seus filhos, consequentemente, estão moldando as características comportamentais da criança (Del Prette \& Del Prette, 1999; Ingberman \& Löhr, 2003). Além disso, de acordo com Soares, Naiff, Fonseca, Cardozo e Baldez (2009), é a partir da educação que o indivíduo entra em contato com suas potencialidades e limitações, desenvolvendo e aperfeiçoando suas competências sociais e cognitivas.

Gomide (2003) afirma que as práticas educativas podem desenvolver tanto comportamentos pró-sociais quanto antissociais, dependendo da frequência e intensidade com que são utilizadas. Assim, a qualidade das relações entre pais e filhos ganha uma importância significativa, uma vez que os pais que propiciam um ambiente familiar acolhedor e tentam construir contextos adequados para o desenvolvimento da criança contribuem para que ela se sinta protegida diante de eventos ameaçadores a que as crianças costumam estar expostas (Del Prette \& Del Prette, 1999). Segundo Gomes (2011), o ambiente familiar socialmente adequado promove a adaptação da criança a uma boa comunicação, ao desenvolvimento da empatia e à expressão de sentimentos, desejos e opiniões, além de facilitar a interação social.

Por outro lado, a exposição da criança a práticas consideradas negativas pode trazer consequências graves e significativas para o seu desenvolvimento. Segundo Ferreira e Marturano (2002), essa exposição ou o baixo envolvimento da criança com o pai ou com a mãe pode contribuir para aumentar sua vulnerabilidade a eventos ameaçadores externos ao contexto familiar.

Segundo Grossi (2003) citado por Brasil e Cia (2013), os pais precisam entender as consequências de seus atos e dos modelos de interação que estabelecem com seus filhos, a fim de atuarem como modificadores de comportamentos indesejados e evitarem o desenvolvimento de problemas futuros. Conforme Bolsoni-Silva, Del Prette e Del Prette (2000), muitos dos problemas dos filhos seriam evitados se os pais fossem orientados a assegurar a qualidade das relações com eles, incluindo a identificação e promoção de suas habilidades interpessoais.

A partir desses conceitos, tendo em vista a importância das práticas educativas parentais sobre o desenvolvimento do repertório socio-habilidoso das crianças, o presente estudo buscou investigar a relação entre práticas parentais e habilidades sociais infantis em crianças de uma escola pública. 


\section{MÉTODO}

\section{Amostra}

A população estudada foi constituída por 28 crianças de 10 a 13 anos de idade, de ambos os sexos, matriculadas no $6^{\circ}$ e $7^{\circ}$ anos do Ensino Fundamental de uma escola pública de Curitiba. O colégio atende a uma população de nível socioeconômico médio.

O critério adotado para a seleção do corpus pesquisado levou em consideração a faixa etária e o aceite das crianças para participarem da pesquisa. A faixa etária foi adotada como critério pelo fato de um dos instrumentos utilizados na pesquisa (Inventário Multimídia de Habilidades Sociais para Crianças - IMHSC), para ter aplicabilidade, deveria ser feito apenas com crianças de uma faixa etária limitada.

A pesquisa atendeu aos requisitos éticos, tendo sido aprovada pelo Comitê de Ética em Pesquisa com Seres Humanos da Faculdade Evangélica do Paraná (Protocolo no 621.516/2014).

\section{Ambiente}

A coleta de dados do presente estudo foi realizada em uma escola pública de nível fundamental de uma cidade do Sul do Brasil. Foi disponibilizada pela escola uma sala com aproximadamente $80 \mathrm{~m} 2$ para a realização da pesquisa.

\section{Instrumentos}

Foram utilizados dois inventários como instrumentos de coleta de dados:

1) Inventário de Estilos Parentais (IEP) - segundo Gomide (2011), esse instrumento tem como objetivo avaliar a maneira utilizada pelos pais para educar seus filhos, bem como avaliar as práticas relacionadas ao desenvolvimento ou à inibição do comportamento antissocial. A aplicação desse instrumento é realizada de forma individual e dura aproximadamente 15 minutos. O questionário é composto por 42 questões que contemplam duas práticas educativas positivas que promovem comportamentos pró-sociais (monitoria positiva e comportamento moral) e cinco negativas vinculadas ao desenvolvimento do comportamento antissocial (punição inconsistente, negligência, disciplina relaxada, monitoria negativa e abuso físico);

2) Inventário Multimídia de Habilidades Sociais para Crianças (IMHSC) - de acordo com Del Prette e Del Prette (2012), esse instrumento tem como objetivo avaliar as habilidades sociais em diferentes situações de interação social, podendo contemplar três alternativas de reação: habilidosa (expressão de sentimentos, empatia, assertividade etc.); não habilidosa passiva (esquiva ou fuga da situação de enfretamento); e não habilidosa ativa (autoritarismo, agressividade etc.). Em cada situação é requerido que o sujeito indique qual a reação que costuma apresentar. Tal avaliação ocorre por meio de 21 situações interpessoais e a aplicação do instrumento também é realizada de forma individual. No presente estudo foi utilizada a versão informatizada do inventário.

\section{Procedimentos}

O presente estudo teve como etapa inicial o contato com a direção da escola, com a finalidade de solicitar autorização para realização da pesquisa e explicar o objetivo e a metodologia que seria utilizada. Após o aceite da escola, foi feito o convite aos alunos. 
Aqueles que se dispuseram a participar da coleta de dados receberam explicações básicas e necessárias a respeito dos objetivos da pesquisa. Nessa ocasião, foi enfatizado que seria mantido extremo sigilo em relação à pesquisa, a fim de garantir a privacidade de identidade e dos dados fornecidos por eles.

Antes da coleta de dados, foi enviado aos pais ou responsáveis, por meio dos alunos, o Termo de Consentimento Livre e Esclarecido (TCLE), que tem como finalidade convidálos a participar da pesquisa e obter as devidas autorizações dos pais.

Após a aprovação do comitê de ética e obtida a autorização da escola e dos pais, foram agendados os dias de aplicação da pesquisa, que foi realizada em dois momentos: primeiro, a aplicação do IEP; segundo, a aplicação do IMHSC. Os inventários foram aplicados pela pesquisadora em sala de aula proporcionada pelo colégio para tal atividade. Antes da aplicação do IEP, a fim de que a pesquisa fosse realizada de forma adequada, a pesquisadora informou às crianças que em cada questão constaria uma frase que elas deveriam responder apontando a frequência (nunca, às vezes e sempre) com que a figura paterna agiria conforme a situação que lhes foi descrita. Posteriormente, foi aplicado o IMHSC, por meio do qual as crianças responderam sobre o que pensavam, o que sentiam e como agiam diante das situações que lhes foram apresentadas. Foi dito às crianças que se por acaso elas nunca tivessem vivenciado a situação descrita, respondessem como achavam que provavelmente se comportariam tendo em vista outras situações semelhantes. Foi explicada também a importância de não deixarem de qualificar nenhuma das questões.

\section{Análise de dados}

Os dados foram analisados de forma quantitativa e interpretados por meio de estatística descritiva, utilizando cálculos percentuais, tabelas comparativas e o teste quiquadrado para verificar o nível de significância entre as duas variáveis: habilidades sociais e práticas parentais.

\section{RESULTADO}

Os resultados do presente estudo foram apresentados em quatro conjuntos. Primeiramente, os dados relativos à amostra estudada; em seguida, os resultados obtidos por meio da aplicação do IEP e do IMHSC; e por último, foram apresentados os resultados da relação entre práticas educativas parentais e habilidades sociais infantis da população estudada. Os resultados foram analisados de modo quantitativo e interpretados por meio de estatística descritiva.

No que se refere à amostra dos 28 participantes, 14 são do sexo feminino, representando 50\% do total, e 14 são do sexo masculino, representando 50\% restantes da amostra. Em relação à idade, seis crianças têm 10 anos, representando 21,42\% do total; dez têm 11 anos, caracterizando 35,71\% da amostra; nove têm 12 anos, contabilizando 32,14\% do total; e três têm 13 anos, representando o menor percentual, 10,71\% dos participantes. Quanto à escolaridade dos participantes, todos estudam no Ensino Fundamental, sendo 12 crianças do $6^{\circ}$ ano, representando $42.85 \%$, e 16 do $7^{\circ}$ ano, que corresponde a $57,14 \%$ do total.

Em relação às práticas parentais utilizadas, verifica-se que há um predomínio de práticas parentais positivas, como pode ser verificado na Figura 1. 


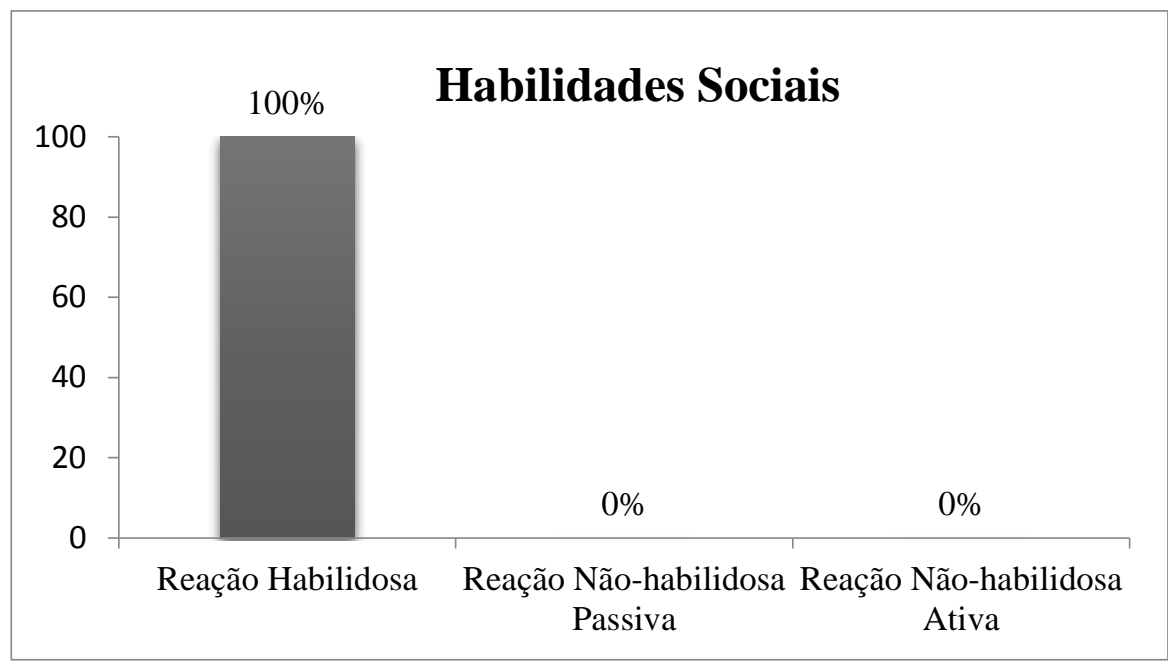

Fonte: Dados retirados do IMHSC.

Figura 1 - Comportamento social infantil categorizado nos tipos de reações comportamentais apresentadas pelos participantes.

Sobre os tipos de práticas parentais positivas utilizadas, observou-se o predomínio do uso da monitoria positiva, representada por $32 \%$ dos participantes, em seguida, alguns participantes apresentaram tanto a monitoria positiva quanto o comportamento moral, que corresponde a $18 \%$ da amostra, e, fechando os percentuais das práticas positivas, o comportamento moral apresentou $7 \%$ do total da amostra. Em relação aos tipos de práticas parentais negativas, houve predomínio da monitoria negativa, com $29 \%$ da amostra, em seguida, o abuso físico totalizou $7 \%$ da amostra, o abuso físico com monitoria negativa totalizou $4 \%$ e, por fim, a negligência, totalizou $3 \%$ da amostra.

Verificou-se que $100 \%$ das crianças apresentaram comportamento socialmente habilidoso, como pode ser observado na Figura 2, em que são mostrados os percentuais de cada reação dos participantes no que diz respeito à avaliação do nível de habilidades sociais.

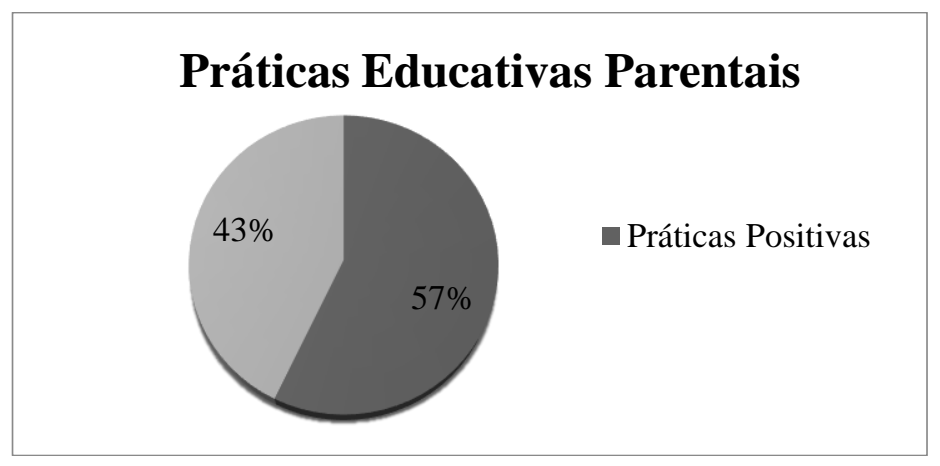

Fonte: Dados retirados da aplicação do IEP.

Figura 2 - Percentual das práticas Educativas Parentais Positivas e Negativas.

Observa-se que tanto as crianças que apresentaram práticas parentais positivas quanto as que apresentaram práticas parentais negativas, demonstraram comportamento social 
habilidoso, como pode ser verificado na Figura 3, em que são demonstrados os resultados da correlação entre as práticas educativas utilizadas pelos pais e as habilidades sociais dos filhos.

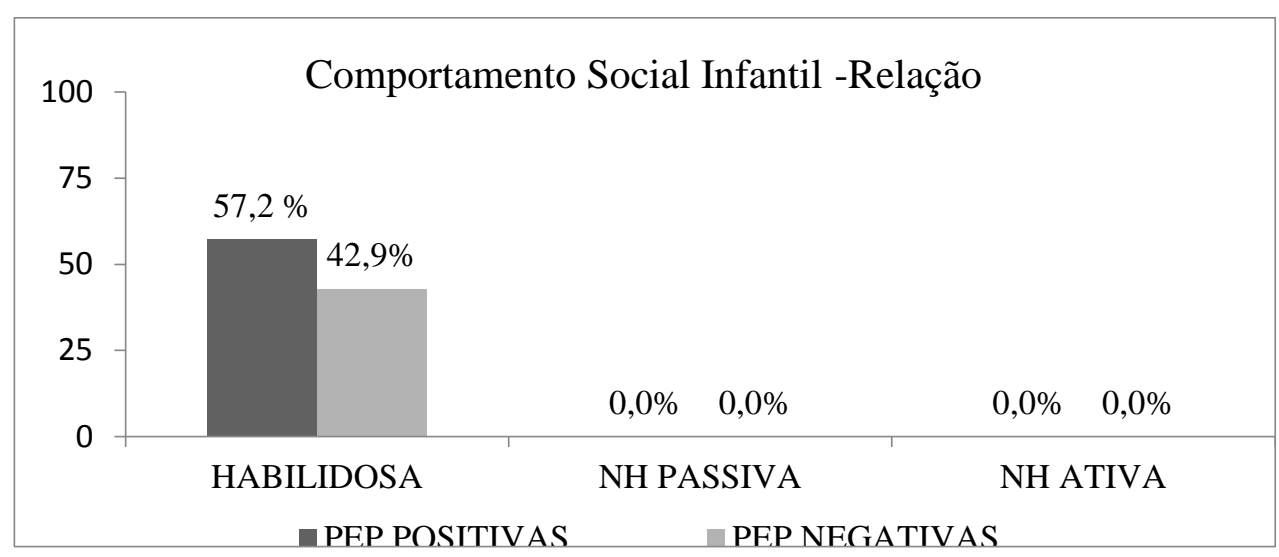

Figura 3 - Comportamento social infantil categorizado nos tipos de reações comportamentais apresentadas pelos participantes e sua relação com praticas parentais positivas e negativas.

Com o objetivo de verificar a relação entre práticas parentais e habilidades sociais, foi utilizado o teste qui-quadrado. Para obter uma diferença significativa, o valor deve ser maior ou igual a 0,05 . No presente estudo, o valor foi de 0,04496 . Portanto, não foi possível verificar se práticas parentais positivas são preditoras de comportamento infantil socialmente habilidoso e se práticas parentais negativas são preditoras de baixo repertório socio- habilidoso. Verificou-se que não houve relação entre as variáveis de práticas parentais e habilidades sociais.

\section{DISCUSSÃO}

No presente estudo, por meio dos resultados obtidos, observou-se que todas as crianças apresentaram comportamento socialmente habilidoso, representando $100 \%$ da amostra. Segundo Del Prette e Del Prette (2005), um repertório elevado de habilidades sociais pode proporcionar o desenvolvimento de comportamentos considerados socialmente adequados. Verifica-se, dessa forma, que os resultados deste estudo são sugestivos de que as crianças participantes da pesquisa possivelmente apresentem repertório de habilidades sociais elevado. Del Prette e Del Prette (2011) confirmam a importância do comportamento habilidoso ao ressaltar que as habilidades sociais são competências que podem auxiliar o bom desenvolvimento de relacionamentos sociais positivos, visto que contribuem para a iniciação e manutenção desses relacionamentos; cooperam para a aceitação dos colegas; e proporcionam um ajustamento escolar adequado. Del Prette e Del Prette (2005) também afirmam que um baixo repertório de comportamentos socio-habilidosos pode colaborar significativamente para o desenvolvimento de comportamentos antissociais e, possivelmente, para problemas psicológicos. Um repertório elevado de habilidades sociais em um indivíduo facilita o estabelecimento de relações saudáveis com outras pessoas que 
estão fora de seu contexto familiar, permitindo, assim, que ele tenha condições adequadas de se adaptar a diferentes situações e tenha capacidade de enfrentar adversidades.

A fim de compreender mais claramente o aspecto socioeconômico relacionado ao tema do presente estudo, é válida uma reflexão a partir de alguns autores, alguns deles com trabalhos desenvolvidos recentemente sobre o mesmo assunto. Os estudos de Madalozzo (2013), por exemplo, serviram como um referencial significativo de investigação para a presente pesquisa, pois a autora teve como objetivo verificar se existe correlação entre práticas parentais e comportamentos socialmente habilidosos de crianças do Ensino Fundamental que estudam em uma escola particular da região Sul do Brasil. A partir de um corpus bastante parecido com o escolhido para o presente trabalho, Madalozzo (2013) realizou sua pesquisa com 30 crianças entre 10 e 12 anos, matriculadas no $6^{\circ}$ e $7^{\circ}$ anos. Em sua pesquisa, a autora verificou que a maioria dos participantes apresentou comportamento socialmente habilidoso e práticas educativas parentais positivas. Todas as crianças que apresentaram práticas educativas positivas apresentaram também comportamento socialmente habilidoso. Porém, das que apresentaram práticas educativas negativas, 85,7\% demonstraram comportamento socialmente habilidoso e 14,3\% comportamento não habilidoso passivo. No entanto, com o estudo de Madalozzo (2013), não foi possível verificar a correlação entre as duas variáveis.

Dessa forma, no que diz respeito ao nível socioeconômico, a pesquisa de Madalozzo (2013) apontou que crianças estudantes de escola particular apresentam um bom desempenho em habilidades sociais. Os autores Bandeira, Rocha, Freitas, Del Prette e Del Prette (2006) sugerem que pode haver uma possível relação entre o nível social e o desenvolvimento de habilidades sociais, conforme a pesquisa que os autores realizaram sobre habilidades sociais e diferenças sociodemográficas em estudantes de Ensino

Fundamental. A pesquisa apontou que crianças de escola particular apresentam maior competência acadêmica do que as de escola pública, sendo a competência acadêmica relacionada com as habilidades sociais. No entanto, esse resultado é diferente do presente estudo, em que todas as crianças apresentaram comportamento socio-habilidoso e são estudantes de escola pública. Em contraposição, o estudo realizado por Robalinho (2013) verificou que o tipo de escola que a criança frequenta não influi sobre problemas de comportamento, assim como também a classe econômica não prediz de forma estatisticamente significativa o repertório socio-habilidoso das crianças. $\mathrm{O}$ que se sugere diante dessa diferença é que crianças pertencentes a escola pública geralmente pertencem a família com renda inferior (Dunker, Fernandes \& Carreira Filho, 2009) e, dessa forma, esse aspecto poderia limitar o acesso dela a um repertório diferenciado e ampliado de interação social, em que as habilidades sociais são valorizadas (Robalinho, 2013). O resultado da presente pesquisa corrobora com os achados de Robalinho, em que não se verifica relação entre comportamento socio-habilidoso e nível social. Dessa forma, o presente estudo também apontou que, mesmo sendo estudantes de escola pública, todas as crianças avaliadas no corpus apresentaram comportamento socialmente habilidoso. Sugere-se, então, que futuras pesquisas invistam em analisar a relação entre habilidades sociais e nível social.

Em relação à análise dos resultados adquiridos com a aplicação do IEP, faz-se necessário destacar a importância da família sobre o desenvolvimento da criança. Segundo Carvalho (2006) citado por Sousa (2012), a família é o primeiro grupo responsável pela socialização da criança. Sousa (2012) acrescenta que independentemente de como é formada, a família passa a ser uma instituição essencial, pois é nela que se formam os 
primeiros valores. No presente estudo, em relação a esse aspecto, verificou-se a predominância de práticas parentais positivas, representadas por $57 \%$ da amostra. Dentre as práticas parentais positivas verificadas, observou-se a predominância de monitoria positiva exercida pelos pais, representando $32 \%$ do total, e $18 \%$ da amostra apresentou monitoria positiva somada ao comportamento moral. Segundo Gomide (2011), a monitoria positiva tem como característica principal o envolvimento dos pais com os filhos, ao propiciarem um ambiente de escuta e estarem disponíveis para ajudá-los em suas necessidades e na resolução de problemas. Essa prática envolve também a expressão de afeto, a determinação de limites e a supervisão de atividades da criança (Gomide, 2011). Para Gomide (2011), pais que utilizam essa prática de educar são mais presentes na vida dos filhos e, assim, reforçam o comportamento positivo. Esses comportamentos facilitam o não desenvolvimento de comportamentos antissociais. Pais que fazem uso da monitoria positiva fornecem orientação e dão a atenção devida aos comportamentos da criança que são considerados adequados.

Conforme apontam Ferreira e Marturano (2002), a exposição da criança a práticas parentais inadequadas, ou a pouca interação com o pai ou com a mãe, pode contribuir para fatores de risco ao desenvolvimento da criança. Com isso, há um aumento, de sua fragilidade diante de eventos ameaçadores que estão fora do seu contexto familiar, possibilitando também que haja um aumento de ocorrência de problemas comportamentais futuros. Com relação às práticas parentais negativas, embora o percentual identificado seja inferior ao das práticas positivas, nota-se que é um alto percentual, representando $43 \%$ do total. Observouse no presente estudo a predominância de monitoria negativa sobre o percentual de práticas negativas utilizadas pelos pais, representando $29 \%$ do total da amostra, além de estar presente em mais $4 \%$ da amostra juntamente com o abuso físico. A monitoria negativa é caracterizada pela demasiada fiscalização da vida dos filhos e pelas instruções repetitivas, as quais os filhos costumam não seguir. Eles passam a ter o hábito de se comportarem agressivamente para proteger dos pais a sua privacidade. Isso, então, propicia um ambiente familiar estressante e sem diálogo (Gomide, 2003).

Considerando a correlação entre práticas educativas parentais e habilidades sociais infantis, no presente estudo verificou-se que não há correlação entre práticas parentais e comportamento socialmente habilidoso, dados que corroboram com os achados de Madalozzo (2013). No estudo de Madalozzo (2013) foi verificada a não correlação entre práticas educativas e habilidades sociais, em que 96,67\% dos participantes demonstraram comportamento socialmente habilidoso, $3,33 \%$ apresentaram comportamento não habilidoso passivo e $0 \%$ apresentaram comportamento não habilidoso ativo. Esses dados podem ser indicativos de que o ambiente social como um todo, e não apenas o familiar, pode contribuir para o desenvolvimento de habilidades sociais consideradas adequadas. Segundo Baraldi e Silvares (2003), quando as crianças são inseridas em um novo contexto, como a escola, por exemplo, espera-se que elas ampliem seu repertório de habilidades sociais. Os autores complementam que o aperfeiçoamento dessas habilidades pode prevenir o aparecimento de comportamentos agressivos ou considerados inadequados. Del Prette e Del Prette (2005) acrescentam que o processo de socialização não acontece apenas no contexto familiar, onde se inicia, mas se expande a outros meios, como escola e vizinhança, por exemplo.

Embora o presente estudo tenha constatado inexistência de correlação, é importante destacar o papel dos pais no desenvolvimento de habilidades sociais nos filhos. Segundo 
Del Prette et al. (1992), a educação parental é indispensável para que haja competência social, pois para haver competência o indivíduo precisa saber quem está direcionando-o e equilibrando reforçadores de práticas positivas, ou, ao menos, garantindo seus direitos humanos básicos.

\section{Considerações finais}

Conclui-se que as duas variáveis estudadas (práticas parentais e habilidades sociais) são de extrema importância para compreensão de como elas se organizam. No entanto, devem ser avaliadas isoladamente, uma vez que no presente estudo não se verificou relação entre elas.

Levantou-se a hipótese de que a ausência de correlação entre práticas parentais e habilidades sociais pode estar associada ao contexto social como um todo no qual a criança está inserida, e não apenas ao contexto familiar. Tendo em vista que a escola e a vizinhança, por exemplo, podem ser contextos de aprendizagem de novos comportamentos, também contribuem para a ampliação do repertório social da criança.

Com a presente pesquisa verificou-se que crianças de escola pública podem apresentar alto índice de habilidades sociais, pois, conforme demonstrado com os dados, apresentaram bom repertório socio-habilidoso.

Para futuras pesquisas, sugere-se o aprofundamento de estudos a respeito de habilidades sociais de crianças estudantes de escola pública e de escola particular, com foco especificamente em práticas educativas parentais maternas e paternas.

\section{Referências}

Bandeira, M., Rocha, S. S., Freitas, L. C., Del Prette, Z. A. P., \& Del Prette, A. (2006).

Habilidades sociais e variáveis sociodemográficas em estudantes do ensino fundamental. Psicologia em Estudo, 11(3), 541-549. doi: 10.1590/S141373722006000300010

Baraldi, D. M., \& Silvares, E. F. M. (2003). Treino de habilidades sociais em grupo com crianças agressivas, associado à orientação dos pais: análise empírica de uma proposta de atendimento. In A. Del Prette, \& Z. A. P. Del Prette (Orgs.), Habilidades sociais, desenvolvimento e aprendizagem: questões conceituais, avaliação e intervenção (pp. 235-258). Campinas, SP: Alínea.

Batista, E. C., Oliveira, B. A., \& Pires, S. L. (2011). A influência da família na aquisição de modelos agressivos pelas crianças. Psicologado, (Paginação Irregular). Recuperado de https://psicologado.com/psicologia-geral/desenvolvimento-humano/a-influenciada-familia-na-aquisicao-de-modelos-agressivos-pelas-criancas

Bolsoni-Silva, A. T., Del Prette, A., \& Del Prette, Z. A. P. (2000). Relacionamentos pais-filhos: um programa de desenvolvimento interpessoais em grupo. Psicologia Escolar e Educacional, 3(3), 203-215. Recuperado de http://www.rihs.ufscar.br/wpcontent/uploads/2015/02/Relacionamento-pais-filhos-um-programa-dedesenvolvimento-interpessoal-em-grupo..pdf 
Bolsoni-Silva, A. T., \& Marturano, E. M. (2002). Práticas educativas e problemas de comportamento: Uma análise à luz das habilidades sociais. Estudos de Psicologia, 7(2), 227-235. doi: 10.1590/S1413-294X2002000200004

Brasil, S. E. R., \& Cia, F. (2013). Pais e filhos: habilidades sociais educativas parentais e habilidades sociais infantis. VIII Encontro da Associação Brasileira de Pesquisadores em Educação Especial, (2694-2702). (Trabalho apresentado no VII Congresso Brasileiro Multidisciplinar de Educação Especial, Londrina, PR.)

Cia, F., Pereira, C. S., Del Prette, Z. A. P., \& Del Prette, A. (2006). Habilidades sociais parentais e o relacionamento entre pais e filho. Psicologia em Estudo, 11(1), 73-81. Recuperado de http://www.scielo.br/pdf/pe/v11n1/v11n1a09.pdf

Del Prette, A., \& Del Prette, Z. A. P. (1999). Psicologia das Habilidades Sociais: terapia e educação. Petrópolis, RJ: Vozes.

Del Prette, A., \& Del Prette, Z. A. P. (2005). Psicologia das Habilidades Sociais na Infância: teoria e prática. Petrópolis, RJ: Vozes.

Del Prette, A., \& Del Prette, Z. A. P. (2011). Psicologia das Habilidades Sociais: Diversidade teórica e suas implicações. Petrópolis, RJ: Vozes.

Del Prette, A., \& Del Prette, Z. A. P. (2012). Inventário Multimídia de Habilidades Sociais para Crianças (IMHSC-Del-Prette): manual do examinador. São Paulo: Casa do Psicólogo.

Del Prette, A., Del Prette, Z. A. P., \& Branco, U. V. C. (1992). Competência social na formação do psicólogo. Paidéia, 2, 40-50. doi: 10.1590/S0103-863X1992000200005

Dunker, K. L. L., Fernandes, C. P. B., \& Carreira Filho, D. (2009). Influência do nível socioeconômico sobre comportamentos de risco para transtornos alimentares em adolescentes. Jornal Brasileiro de Psiquiatria, 58(3), 156-161. doi: 10.1590/S004720852009000300003

Ferreira, M. C. T., \& Marturano, E. M. (2002). Ambiente familiar e os problemas de comportamento apresentados por crianças com baixo desempenho escolar. Psicologia Reflexão e Crítica, 15(1), 35-44. doi: 10.1590/S010279722002000100005

Gomes, C. A. (2011). Práticas parentais positivas como estratégia para o aprendizado de comportamentos pró-sociais. [S. I.]: Revista Lationamericana de Desarrollo Humano. Boletim no 70, 10-14. Recuperado de http://www.revistahumanum.org/revista/praticas-parentais-positivas-comoestrategia-para-o-aprendizado-de-comportamentos-pro-sociais/

Gomide, P. I. C. (2003). Estilos parentais e comportamento anti-social. In A. Del Prette \& Z. Del Prette (Orgs.). Habilidades sociais, desenvolvimento e aprendizagem: questões conceituais, avaliação e intervenção (p.21-60). Campinas, SP: Alínea. 
Gomide, P. I. C. (2011). Inventário de Estilos Parentais: modelo teórico, manual de aplicação, apuração e interpretação. (2 ed.). Petrópolis, RJ: Vozes.

Gomide, P. I. C. (2011). Pais presentes, pais ausentes: regras e limites. (10 ed.). Petrópolis, RJ: Vozes.

Gomide, P. I. C. (2012). Comportamento moral: uma proposta para o desenvolvimento das virtudes. (2 ed.). Curitiba: Juruá.

Ingberman, Y. K., \& Löhr, S. S. (2003). Pais e filhos: Compartilhando e expressando sentimentos. In F. C. Conte \& M. Z. S. Brandão (Orgs.), Falo? Ou não falo? Expressando sentimentos e comunicando idéias (pp. 85-95). Arapongas, PR: Mecenas.

Madalozzo, A. C. (2013). Práticas educativas parentais e habilidades sociais de crianças que freqüentam uma escola particular de Curitiba. Trabalho de Conclusão de Curso, Faculdade Evangélica do Paraná. Curitiba, Paraná.

Patrian, A. C. A., Rios, K. S. A., \& Williams, L. C. A. (2013). Validade de critério do Inventário de Potencial para Abuso Infantil (CAP). Paidéia, 23(54), 43-51. doi: 10.1590/198243272354201306

Robalinho, I. G. C. (2013). Relação entre automonitoria, problemas de comportamento e habilidades sociais na infância. Dissertação de Mestrado, Universidade Federal de São Carlos, São Carlos, SP.

Salvo, C. G., Silvares, E. F. M., \& Toni, P. M. (2005). Práticas educativas como forma de predição de problemas de comportamento e competência social. Estudos de Psicologia, 22(2), 187-195. doi: 10.1590/S0103-166X2005000200008

Soares, A. B., Naiff, L. A. M., Fonseca, L. B., Cardozo, A., \& Baldez, M. O. (2009). Estudo comparativo de habilidades sociais e variáveis sociodemográficas de professores. Psicologia: Teoria e Prática, 11(1), 35-49. Recuperado de http://pepsic.bvsalud.org/scielo.php?script=sci_arttext\&pid=S151636872009000100004\#end

Sousa, J. P. (2012). A importância da família no processo de desenvolvimento da aprendizagem da criança. Trabalho de Conclusão de Curso para obtenção do título de Especialista em Psicopedagogia Clínica e Institucional, Instituto de Estudos Superiores do Ceará - INESC, Pró-reitoria de Educação Continuada, Fortaleza, CE.

Recebido/received: 28/10/2015

Aprovado / Approved: 22/02/2016 